\title{
Deep learning: To better understand how human activities affect the value of ecosystem services
}

\author{
Chang Liu ${ }^{1}$, Yi Qi ${ }^{1}$, Hong $\mathrm{Yao}^{2}$, Shan $\mathrm{Li}^{1}$, Ping Sun ${ }^{1}$, and Tianhua $\mathrm{Ni}^{1}$ \\ ${ }^{1}$ Nanjing University \\ ${ }^{2}$ Nantong University
}

May 5, 2020

\begin{abstract}
The increase in human activities is one of the important factors affecting the value of ecosystem services. However, understanding of the driving mechanisms of human activities is limited. We established a deep learning model to approximate the ecosystem service value (ESV) of Nanjing City using 23 socioeconomic factors. A multi-view analysis was then conducted on feasible impact mechanisms using model disassembly. The results indicated that factors such as the proportion of ecological waters in the land-use structure and secondary industry output value had their own independent effects on ESV. Other intrinsically related factors, for instance, industrial water consumption and industrial electricity consumption, were likely to be composited together to affect ESV.
\end{abstract}

\section{Introduction}

Ecosystem services are the benefits that people obtain from various ecosystems that can be described and measured (Tamayo et al. 2018; Costanza et al. 1997). Mendelsohn and Olmstead (2009) described the value of ecosystem services (ESV) as "the sum of what all members of society would be willing to pay" for "the economic benefit provided by environmental products or service" (Mendelsohn \& Olmstead 2009). Hence, the estimation of ESV can make a vital contribution to biodiversity protection and sustainable development (Billé et al. 2012). Assessments of ESV at the national, regional, basin and even single ecosystem levels can show how these services support our lives and how people develop natural resources rationally (Wei et al. 2018). The valuation methods now available are highly developed and can be mainly divided into behavioral (revealed preference) methods and attitudinal (stated preference) methods (Mendelsohn and Olmstead 2009). Behavioral methods attempt to calculate the environmental value of goods indirectly through market analysis (Braden et al. 2010; Phaneuf et al. 2008; Harrington \& Portney 1987). Attitudinal methods use subjectively designed surveys to create a table of ecological value equivalents. Two common valuation systems include the system created by Costanza in 1997 (Costanza et al. 1997) and the millennium ecosystem assessment framework (Alcamo 2003).

However, the understanding of ESV is not comprehensive because multiple types of service interrelate in complex and dynamic ways (Spake et al. 2017). The current research perspectives on ESV consider it to be the result of a process: "human-driven factors of ecosystem change ecosystem process and functions ecosystem services". "Human-driven factors of ecosystem change" can be interpreted as basic socioeconomic conditions, including population, GDP, industry structure, and energy consumption. "Ecosystem process and functions" can be represented by land and land cover change at the geospatial level, which is traditionally the most important part of the information used to estimate ESV (Barbier et al. 2011). However, how ESV interacts with socioeconomic factors remains ambiguous (Meacham et al. 2016), which leads to difficulties in the application of ESV in ecological management. In other words, even if a low ESV area is identified, we still do not know how to promote it efficiently through regional planning or industry regulation. Studies 
started to include the socioeconomic drivers of ESV into consideration for the implementation of responsive policies. Yang et al. (2019) found that ESV is tightly correlated with socioeconomic status. Wu et al. (2019) found nonlinear relations between GDP and ESV and between population density and ESV, but no more complete causality was explained.

As one kind of machine learning algorithm, deep learning is a multilayer perceptron neural network (Reichstein et al. 2019). It offers significant breakthroughs in solving classification and nonlinear regression problems (Sze et al. 2017). Deep learning can extract the valid features of data input through complex computational models and represent them at a higher level of abstraction, eventually achieving complex self-learning functions through multiple transformations and combinations (LeCun et al. 2015). Traditional evaluation and analysis methods are often not sufficiently effective in describing the continuous and quantitative rules in a complicated ecosystem (Moore et al. 2017). Deep learning may be an effective tool for dealing with this problem.

In this work, deep learning was used to explore the relationships between "human drivers of ecosystem change" and "ESV" on a dataset from Nanjing, China. The city of Nanjing is one of the megacities in the Yangtze River basin; it has experienced rapid economic development since the 1970s that is still occurring today (Li et al. 2016) (Figure S1). At the end of the 20th century, the urbanization of Nanjing entered an accelerated phase, which led to a rapid increase in population, unreasonable industrial structure, unbalanced land use, high energy consumption, and environmental degradation (Yuan et al. 2018; Shi et al. 2019). Over the last two decades, the population has increased from $3 \mathrm{M}$ to $8.5 \mathrm{M}$, and its GDP has increased from 338.12 billion CNY in 2008 to 1171.51 billion CNY in 2018. As an ecologically sensitive area, the changes in its ecological system and services have been continuously monitored and studied. Taking ESV as a parameter of the ecosystem, a better understanding of their internal driving mechanism will be conducive to optimizing local policies and regional planning (Shiferaw et al. 2019).

\section{Methods}

\section{Data preprocessing}

The Terrestrial Ecosystem Service Value Distribution Database used in this study was constructed by Xie using attitudinal methods (http://www.resdc.cn) (Table S1).

According to China's green development policy (Ji et al. 2017), the factors related to ecological conditions and sustainability were divided based on six aspects: resource utilization, environmental governance, environmental quality, ecological protection, growth quality, and green life. Due to the spatial scale of this study, natural conditions such as temperature, perception, and humidity are relatively similar across the city, so they were not used as model input for differentiation. Taking the correlation with ESV and anthropogenic controllability into account, 23 indexes from 2015 were chosen and altered from three perspectives (Table S1) as input for the following ESV deep learning model. The data resources and spatial revolution of raster data are shown in Table S1.

Multidata fusion on the same scale (Openshaw 1984; Perkins 2017; Hodgkinson and Andresen 2019) is necessary to make labeled samples meet the common format and quantity requirements for deep learning model training. Considering the area of Nanjing and the ecological significance of ESV, we used a $2 * 2 \mathrm{~km}$ grid for data processing by grid transformation. A total of 2191 grid units were obtained as samples. The socioeconomic data were allocated by key weighting factors (Table S2) using Eq. 1. Spatial socioeconomic data with a resolution of $2 * 2 \mathrm{~km}$ were obtained.

$\mathrm{Af}_{i}=\mathrm{As}_{i} \times \frac{\mathrm{Wf}_{i}}{\mathrm{Ws}_{i}}($ Eq. 1)

$A f_{i}$ : the values in $2^{*} 2 \mathrm{~km}$ units of the ith (No.) allocated indicators. As $s_{i}$ : the total value of the ith (No.) allocated indicators in Nanjing City. Wf $f_{i}$ : the values in $2^{* 2} \mathrm{~km}$ units of the ith (No.) weighting factors. Ws: the total value of the ith (No.) weighting factors in Nanjing City.

Finally, data standardization was conducted as a standard procedure before training. Standard deviation 
standardization was used to eliminate the influence of the magnitudes. The land-use factors were represented by individual area proportions (from $0 \%$ to $100 \%$ ) for each type, which were then individually standardized.

\section{Data modeling}

Because of the complexity of the anthropogenic driving mechanisms, the relations among the 23 independent variables and ESV cannot be described by the conventional linear model. We used a feed-forward dense network as the deep learning model.

The network consists of 8 layers (4 dense layers), including 6 hidden layers in the network. Each layer has a certain number of neurons and activation functions (Table 1). Nonlinear activation functions such as the rectified linear unit (ReLU) were introduced in the $3^{\text {rd }}$ and $5^{\text {th }}$ hidden layers to learn the nonlinearity. The ReLU function was used to avoid vanishing gradient problems. Additionally, the dropout rate was set to 0.3 in all dropout layers to avoid overfitting problems.

We partitioned $70 \%$ of the 2191 units as training samples and $30 \%$ as testing samples. In the training phase, the optimizer and loss function were established based on adaptive moment estimation (ADAM) and the mean square error (MSE). After conventional model optimizations were performed, the above hyperparameters were determined. The corresponding model was trained and used in the study.

Table 1. The configuration of the model

\begin{tabular}{llll}
\hline Layer & Operation & Parameter & Parameter \\
\hline Input layer & & 23 & Socioeconomic factors \\
1-2-hidden & dense & 128 & linear \\
& dropout & 0.3 & 0.3 \\
3、4-hidden & dense & 256 & tanh \\
& dropout & 0.3 & 0.3 \\
5,6 -hidden & dense & 16 & ReLU \\
& dropout & 0.3 & 0.3 \\
Output layer & dense & 1 & linear \\
\hline
\end{tabular}

\section{Model analysis}

We observed how ESV (Y) responded to the change in each influence factor (X) by sampling continuously in the range of each input $\mathrm{X}$. In the course of the concrete analysis, other factors were kept as the mean of samples, and the values of the target factors were changed by adopting control variables. In addition, the range of target $\mathrm{X}$ was regarded as its definition domain, called the sampling domain. The range of ESV is called the response domain. The influence intensity of every $\mathrm{X}$ factor can be judged according to the corresponding response domain, and the influence mode and potential mechanism can be judged according to the variation trend of the function.

\section{Results and discussion}

\section{Model performance}

The model was trained for 200 epochs and showed a significant convergence trend. In terms of precision, the Nash-Sutcliffe efficiency and root MSE (RMSE)-observation standard deviation ratio (RSR) were used as indicators to reflect the model performance and reached values of 0.51 and 0.70 respectively, indicating "satisfactory" performance. Spatially, the observed value and predictive value of each sample were visualized with one set of legends showing similar spatial characteristics (Figure 1). However, overall, the sum of the predictive values was lower than the ground truth sum. 


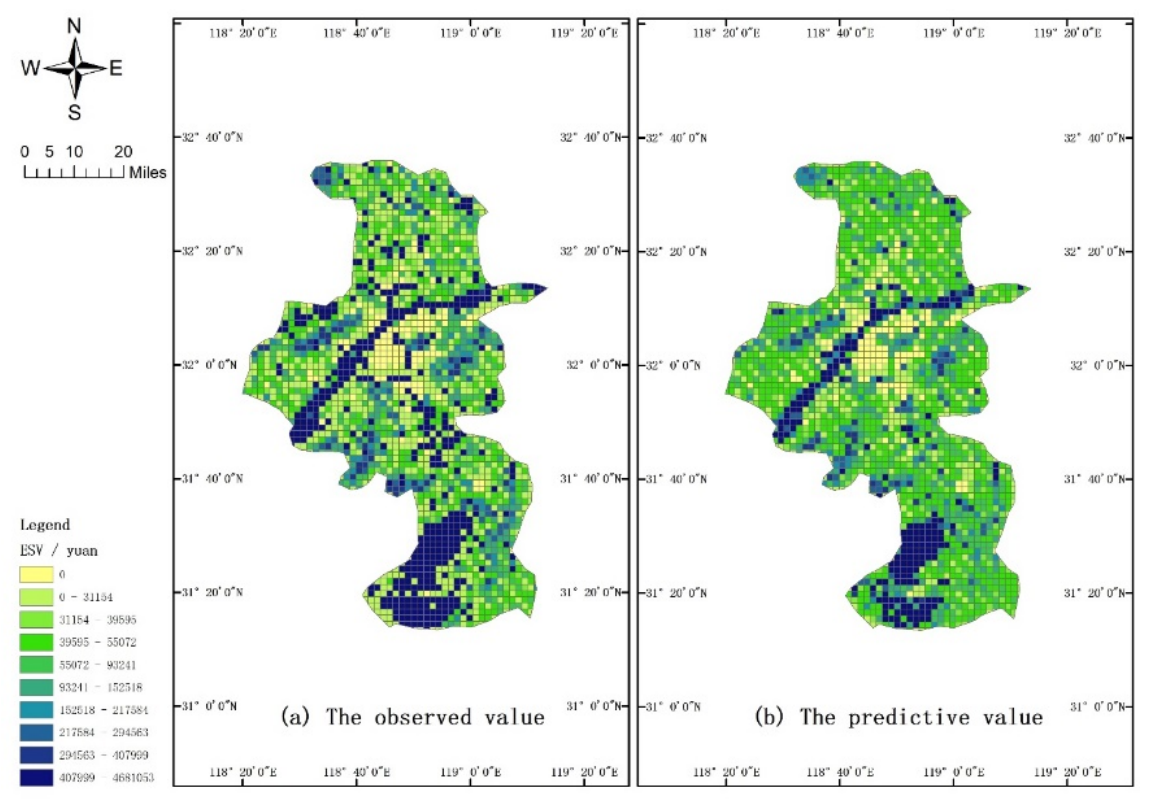

Figure 1. (a) Map of the observed ESV value in Nanjing. (b) Map of the predictive ESV value in Nanjing.

\section{Single-factor response}

$23 \mathrm{X}$ factors were divided into three categories, extremely significant influence intensity (ES), significant influence intensity (S), and nonsignificant influence intensity (NS), according to the range of the response domain (Table 2).

Table 2. The influence intensity and influence mode of $23 \mathrm{X}$ factors

\begin{tabular}{|c|c|c|c|}
\hline Index & Original sampling domain & Standardized sampling domain & The range of 1 \\
\hline $2^{\text {nd }}$ industry output value (million yuan) & $(0,14000)$ & $(0,14)$ & $0.310(\mathrm{ES})$ \\
\hline Water area $(\%)$ & $(0,100)$ & $(0,100)$ & $0.236(\mathrm{ES})$ \\
\hline GDP (million yuan) & $(0,10000)$ & $(0,15)$ & $0.181(\mathrm{~S})$ \\
\hline Industrial water consumption & $(0,40)$ & $(0,14)$ & $0.178(\mathrm{~S})$ \\
\hline Light index & $(-100,600)$ & $(-2,5)$ & $0.162(\mathrm{~S})$ \\
\hline $3^{\text {rd }}$ industry output value (million yuan) & $(0,1750)$ & $(-1,5)$ & $0.154(\mathrm{~S})$ \\
\hline Agricultural electricity consumption & $(0,0.35)$ & $(-2,3)$ & $0.138(\mathrm{~S})$ \\
\hline Water consumption (kt) & $(0,70)$ & $(0,20)$ & $0.138(\mathrm{~S})$ \\
\hline Tourism output (million yuan) & $(0,80)$ & $(-6,1)$ & $0.137(\mathrm{~S})$ \\
\hline $1^{\text {st }}$ industry output value (million yuan) & $(0,35)$ & $(-2,3)$ & $0.13(\mathrm{~S})$ \\
\hline Woodland area $(\%)$ & $(0,100)$ & $(0,100)$ & $0.103(\mathrm{~S})$ \\
\hline Grassland area (\%) & $(0,100)$ & $(0,100)$ & 0.094 (NS) \\
\hline Residential electricity consumption (kw) & $(0,20)$ & $(-1,5)$ & $0.089(\mathrm{NS})$ \\
\hline NDVI & $(0,4)$ & $(-3,3)$ & $0.089(\mathrm{NS})$ \\
\hline Population (person) & $(0,250000)$ & $(0,17.5)$ & 0.088 (NS) \\
\hline Agricultural water consumption (kt) & $(0,2.5)$ & $(-2,3)$ & $0.083(\mathrm{NS})$ \\
\hline Electrical consumption $(\mathrm{kw})$ & $(0,800)$ & $(0,20)$ & $0.079(\mathrm{NS})$ \\
\hline Construction industry output (million yuan) & $(0,175)$ & $(-1,5)$ & $0.071(\mathrm{NS})$ \\
\hline Industrial electricity consumption (kw) & $(0,1000)$ & $(0,14)$ & $0.067(\mathrm{NS})$ \\
\hline Residential water consumption (kt) & $(0,20)$ & $(-1,5)$ & $0.051(\mathrm{NS})$ \\
\hline Construction land area $(\%)$ & $(0,100)$ & $(0,100)$ & $0.042(\mathrm{NS})$ \\
\hline
\end{tabular}




\begin{tabular}{llll}
\hline Index & Original sampling domain & Standardized sampling domain & The range of r \\
\hline Unused land area (\%) & $(0,100)$ & $(0,100)$ & 0.037 (NS) \\
Cultivated area (\%) & $(0,100)$ & $(0,100)$ & 0.017 (NS) \\
\hline
\end{tabular}

The "2 ${ }^{\text {nd }}$ industry output value" was an extremely significant (ES) factor with the highest range in the response domain. The monotonic decreasing function of the " ${ }^{\text {nd }}$ industry output value" and ESV meant that a more developed $2^{\text {nd }}$ industry led to a lower ESV (Figure 2a). In addition, there were a series of $\mathrm{X}$ factors with a relatively high range of response domains and significant influence intensities. Among them, "GDP", "light index" and "tourism output" had a positive impact on ESV, and "industrial water consumption", " $3^{\text {rd }}$ industry output value", "agricultural electricity consumption" and "1st industry output value" had a negative impact on ESV. The function of the relationship between "water consumption" and ESV adopted an inverted U-shaped curve. The inflection point of "water consumption" was approximately $10 \mathrm{kt}$, while ESV reached a maximum value of $810 \mathrm{k}$ (Figure S2).

"Water area" was another extremely significant factor, and the areas of other types of land were all NS factors except "woodland area" (S), which displayed the lowest range in the response domain compared with other significant (S) factors. The "water area", "woodland area" and "unused land area" had a positive impact on ESV (Table 2). In contrast, the "cultivated area" and "construction land area" had a negative impact on ESV. Moreover, the relationship between the "grassland area" and ESV displayed a U-shaped curve that had an inflection point at approximately $80 \%$ of the grassland area (Figure 2b and Figure S2).

Other factors had a relatively low range of response domains, which meant that their influence was not significant. However, the functions capturing the relationship between these NS factors and ESV almost all assumed a U-shaped curve or an inverted U-shaped curve (Figure 2b and Figure S2). All the analyses suggested that there is a response relationship between ESV and socioeconomic conditions. Therefore, the ESV can be improved indirectly by adjusting these factors. However, understanding how to regulate and control the above factors to achieve a balance between ESV and economic development still requires further multifactor coupling research.

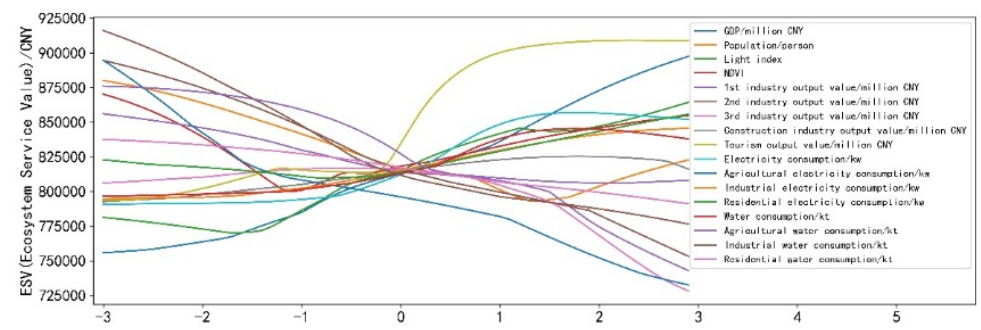

(a)

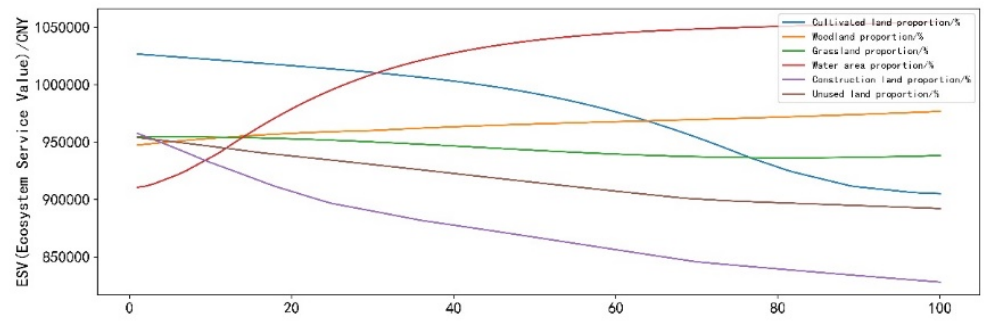

(b)

Figure 2. The functions of the relationships between standardized X factors and ESV

(a) The function of the relationship between nonland-use-type factors (changed from -3 to 3 ) and 
ESV; (b) The function of the relationship between land-use factors (changed from $0 \%$ to 100\%) and ESV.

\section{Multifactor response}

It is difficult to achieve maximum ESV and adjust all socioeconomic factors to the optimum intervals because of the complex coupling influence. We attempted to select several sets of factors with significant interactions to identify which proportions could regulate them for the purpose of maximizing ESV. As a result, "the proportion of construction" and "population", "1 ${ }^{\text {st }}$ industry output value" and "population", and "industrial water consumption" and "industrial electric consumption" were chosen to analyze how they cooperatively influence ESV.

This approach suggested that ESV is most affected by the population (Figure 3a). The population within $4 \mathrm{~km}^{2}$ should be controlled to be less than $20 \mathrm{k}$ or approximately $120 \mathrm{k}$. In addition, ESV dropped sharply with the increase in construction land when the population was $50 \mathrm{k}$. In contrast, ESV declined slowly with the increase in construction land when the population was more than $100 \mathrm{k}$, which suggests that a relatively single distribution of construction land will not place too much pressure on the ecosystem in densely populated centers. However, controlling construction land still has a positive influence on ESV. Therefore, the city center can sacrifice nonconstruction land for infrastructure construction and population accommodation, and it will be necessary for it to reserve ecological space.

The surface of " $1^{\text {st }}$ industry output value" and "population" showed that there were two scenarios that achieve higher ESV (Figure 3b). One scenario was when the population was nearly 0 and the output of the $1^{\text {st }}$ industry was more than 15 million CNY. Under this scenario, the object region had a small population but played an important role in agricultural production. The other scenario was when the population was approximately $150 \mathrm{k}$ and the $1^{\text {st }}$ industry output value was less than 10 million CNY.

Regarding energy consumption, "industrial water consumption" was presumably the limiting factor compared with "industrial electricity consumption" (Figure 3c). Industrial water consumption should be kept below $15 \mathrm{kt}$ if one hopes to achieve a high ESV. When industrial electricity consumption was between 400 and 600 $\mathrm{kw}$, ESV rapidly decreased with increasing industrial water consumption. This finding suggested that water consumption needs to be restricted and reserved in industrial areas.
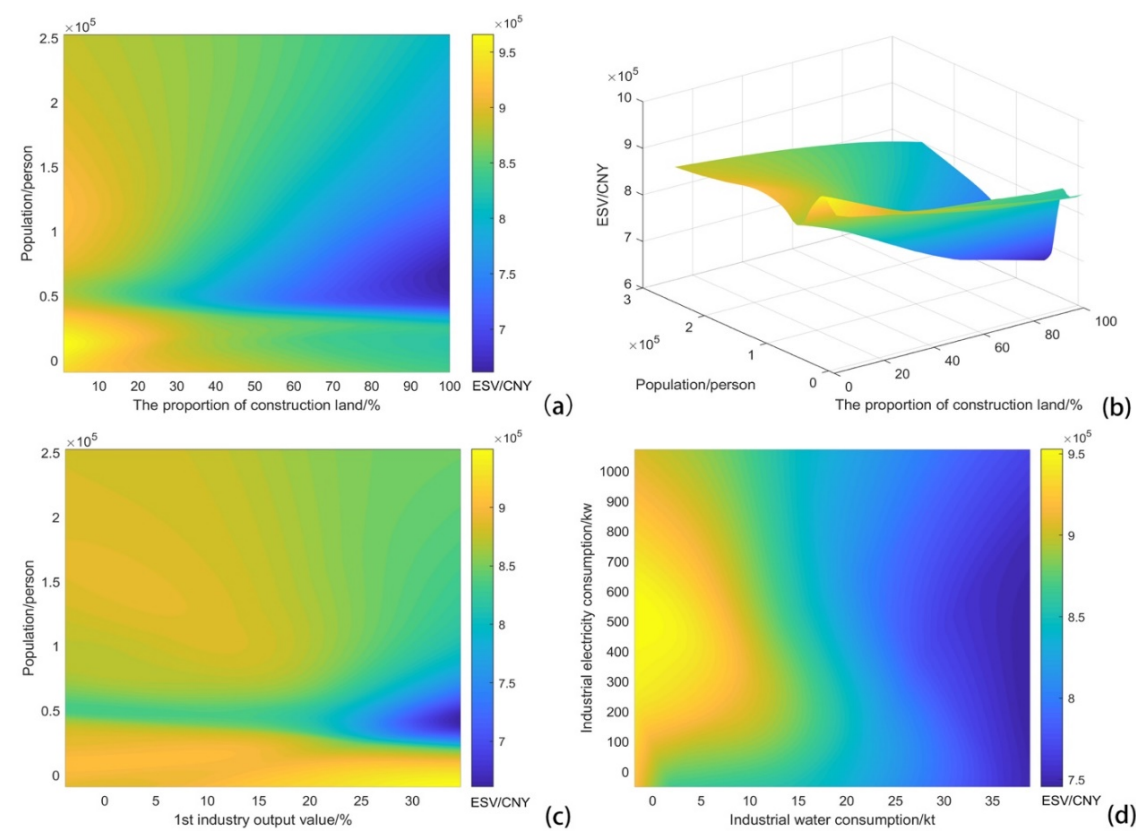

Figure 3 . The surface of ESV and three sets of coupling factors 
(a) The coupling influence of "the proportion of construction" and "population"; (b) The 3D surface of ESV, "the proportion of construction", and "Population"; (c) The coupling influence of " 1 st industry output value" and "population"; (d) The coupling influence of "industrial water consumption" and "industrial electric consumption".

\section{Urban cognizable synergistic features}

As the activation function in the output layer is linear, it is possible to extract cognitive and comprehensible features from the penultimate layer (Yu \& Seltzer 2011). Nine features with bottom-up information were interpreted and understood. Considering the range of $\mathrm{Y}$ and the weight of the features, significant features that contained more information about the corresponding factors were selected. The features were named according to X, which had a great influence on them, except feature 7, which contained information on almost all the factors and features 9 and 15, which contained little information on any factors. Therefore, 6 cognizable synergistic features integrated from multiple factors were extracted, including the urban expansion factor (0.0133), land use-industrial structure-energy consumption structure (0.0146), land use-energy consumption structure, agricultural development (0.0146), city-scale factor (0.0151) and tourism exploitation potential (0.0138) (Table 3). Among these factors, the city-scale factor was the most significant urban cognizable feature with the highest weight (0.0151), and it contained information about GDP, population and tourism output. This finding demonstrated that the deep learning model may predict ESV by quantifying regional characteristics, including land-use structure, energy consumption structure, industrial structure, and city scale. Therefore, it is possible to adjust the urban macro characteristics to maintain or even improve the regional ESV.

Table 3. The extraction and analysis of urban cognizable features

\begin{tabular}{|c|c|c|c|c|}
\hline Number & Weight & Factors contained & The weighted range of $\mathrm{Y}$ & The name of urban cognizable feat \\
\hline \multirow[t]{3}{*}{ Feature 1} & 0.0133 & Light index & 0.000508 & Urban expansion factor \\
\hline & & Cultivated area & 0.000768 & \\
\hline & & Residential electricity consumption & 0.000365 & \\
\hline \multirow[t]{11}{*}{ Feature 3} & 0.0146 & Light index & 0.00083 & Land use-industrial structure-ener \\
\hline & & Cultivated area & 0.000902 & \\
\hline & & Woodland area & 0.00108 & \\
\hline & & Grassland area & 0.000862 & \\
\hline & & Water area & 0.001034 & \\
\hline & & Unused land area & 0.000916 & \\
\hline & & $2^{\text {nd }}$ industry output value & 0.000484 & \\
\hline & & $3^{\text {rd }}$ industry output value & 0.000488 & \\
\hline & & Agricultural electricity consumption & 0.000358 & \\
\hline & & Industrial water consumption & 0.000469 & \\
\hline & & Residential water consumption & 0.000543 & \\
\hline \multirow[t]{10}{*}{ Feature 6} & 0.0146 & Woodland area & 0.00106 & Dynamic land use-energy consur \\
\hline & & Water area & 0.001037 & \\
\hline & & Construction land area & 0.000803 & \\
\hline & & Unused land area & 0.001005 & \\
\hline & & Construction industry output value & 0.000309 & \\
\hline & & Electrical consumption & 0.000628 & \\
\hline & & Industrial electricity consumption & 0.000926 & \\
\hline & & Residential electricity consumption & 0.000424 & \\
\hline & & Water consumption & 0.000347 & \\
\hline & & Agricultural water consumption & 0.000369 & \\
\hline \multirow[t]{3}{*}{ Feature 8} & 0.0143 & Light index & 0.000645 & Agricultural development factor \\
\hline & & Cultivated area & 0.000905 & \\
\hline & & Unused land area & 0.000978 & \\
\hline
\end{tabular}




\begin{tabular}{lllll}
\hline Number & Weight & Factors contained & The weighted range of $\mathrm{Y}$ & The name of urban cognizable fea \\
\hline & & $1^{\text {st }}$ industry output value & 0.000547 & \\
& & Agricultural electricity consumption & 0.00036 & \\
Feature 10 & \multirow{2}{*}{0.0151} & Residential electricity consumption & 0.000439 & \\
& & Water consumption & 0.000379 & City scale factor \\
Feature 13 & \multirow{2}{*}{0.0138} & PDP & 0.000964 & Tourism exploitation potential fac \\
& & Population & 0.001185 & \\
& & NDVI & 0.000885 & \\
& Agricultural water consumption & 0.000846 & 0.000819 & \\
& & Tourism output value & 0.000632 & \\
& Construction land area & 0.000376 & \\
\hline
\end{tabular}

The extraction of urban cognizable synergistic features could be regarded as a form of dimensionality reduction in $23 \mathrm{X}$ factors. Therefore, we compared urban cognizable features with the results of a principal component analysis, which is a widely used technique in machine learning (Monedero et al. 2019). There were 6 principal components, which all contained no more than 2 factors (Table S3). However, we could not give definite practical meaning to the principal components, which meant that the extraction of urban cognizable features has unique advantages as a new dimensionality reduction method.

\section{Conclusion}

The study proposed deep learning as a new, more effective approach to understanding the patterns, dynamics, and driving factors of ESV that are crucial for coping with sustainability challenges. The findings of the model analysis suggested that underlying social and economic conditions presumably influence regional ecological functions through ESV.

Regarding Nanjing City, although the outputs of the $1^{\text {st }}, 2^{\text {nd }}$ and $3^{\text {rd }}$ industries all showed a decreasing trend in ESV, the " $2^{\text {nd }}$ industry output value" had the highest influence intensity, indicating the urgency and necessity of controlling its proportion. We propose that economic development, urbanization, and tourism should be further accelerated and enhanced in Nanjing, because "GDP", "light index", "tourism output" and "residential electricity consumption" all have positive influences on ESV. In addition, there should be singleness in the urban function, which means that city space needs to be separated to serve different functions. The extraction of high-level urban cognizable factors related to ESV in the penultimate layer may be a new dimensionality reduction method, and the analysis suggested that the city scale of Nanjing can truly affect the ESV. As a result, it is possible for decision-makers to provide policy guidance and adjust urban features to realize the coordinated development of the regional economy and ecological functions. For instance, the most suitable city scale can be found that is within the regional ecological carrying capacity.

In this work, the relationship between human socioeconomic development and ESV on the urban scale is at the heart of our research. We built a deep learning model based on the limited socioeconomic factors (X) to cognize it and obtained interesting and meaningful results. Furthermore, our point of view is that there are likely to be obvious differences in the driving mechanisms under diverse regional and scale contexts. Therefore, an important direction for further research is the investigation of more influence patterns and mechanisms on diverse spatial scales and levels of socioeconomic development affecting the change in regional ESV.

\section{Acknowledge}

This work was supported by the Environmental Protection Research Project of Jiangsu Province(No. 2018008)and the Environmental Science and Technology Project of Nanjing(No.201904). The authors thank Prof. Jiangang Xu for valuable comments and discussion.

\section{References}


Alcamo, J. (2003). Ecosystems and human well-being: A framework for assessment. Ecosystems and human well-being: A framework for assessment. Island Press, Washington, DC, USA.

Barbier, E.B., Hacker, S.D., Kennedy, C., Koch, C., Stier, A. \& Silliman, B.R. (2011). The value of estuarine and coastal ecosystem services. Ecol Monogr 81 : 169-193.

Billé, R., Laurans, Y., Mermet, L., Priard, R. \& Rankovic, A. (2012). Valuation without action? On the use of economic valuations of ecosystem services. IDDRI Policy Brief 7 : 1-4.

Braden, J.B., Feng, X., Freitas, L. \& Won, D.H. (2010). Meta-functional transfer of hedonic property values: Application to great lakes areas of concern. ARER 39 : 101-113.

Costanza, R, d'Arge, R., De Groot, R., Farber, S., Hannon, B., Limburg, K., et al. (1997). The value of the world's ecosystem services and natural capital. Nature $387: 253$.

Harrington, W. \& Portney, P.R. (1987). Valuing the benefits of health and safety regulation. J Urban Econ 22 : 101-112.

Hodgkinson, T. \& Andresen, M.A. (2019). Changing spatial patterns of residential burglary and the crime drop: The need for spatial data signatures. J Crim Just 61 : 90-100.

Ji, Q., Li, C. \& Jones P. (2017). New green theories of urban development in china. Sustain Citie Soc 30 : 248-253.

LeCun, Y., Bengio, Y. \& Hinton, G. (2015). Deep learning. Nature521 : 436-444.

Li, B.J., Chen, D.X., Wu, S.H., Zhou, S.L., Wang, T. \& Chen, H. (2016). Spatio-temporal assessment of urbanization impacts on ecosystem services: Case study of nanjing city, china. Ecol Indic71 : 416-427.

Meacham, M., Queiroz, C., Norström, A.V. \& Peterson, G.D. (2016). Social-ecological drivers of multiple ecosystem services: What variables explain patterns of ecosystem services across the norrström drainage basin? Ecol Soc 21 :14.

Mendelsohn, R. \& Olmstead, S. (2009). The economic valuation of environmental amenities and disamenities: Methods and applications. Annu Rev Env Resour 34 : 325-347.

Monedero, D.R., Mezher, A.M., Colomé, X.C., Forné, J. \& Soriano, M. (2019). Efficient k-anonymous microaggregation of multivariate numerical data via principal component analysis. Inform Sciences503 : 417-443.

Moore, D.W., Booth, P., Alix, A., Apitz, S.E., Forrow, D., Huber-Sannwald, E., et al. (2017). Application of ecosystem services in natural resource management decision making. Integr Environ Assess 13 : 74-84.

Openshaw, S. (1984). Ecological fallacies and the analysis of areal census data. Environ Plann A 16 : 17-31.

Perkins, C. (2017). Reflections on 'map design for census mapping'. In: Landmarks in mapping. London; New York: Routledge.

Phaneuf, D.J., Smith, V.K., Palmquist, R.B., Pope, J.C. (2008). Integrating property value and local recreation models to value ecosystem services in urban watersheds. Land Econ 84 : 361-381.

Reichstein, M., Camps-Valls, G., Stevens, B., Jung, M., Denzler, J. \& Carvalhais, N. (2019). Deep learning and process understanding for data-driven earth system science. Nature 566 : 195-204.

Shi, G., Shan, J., Ding, L., Ye, P., Li, Y. \& Jiang, N. (2019). Urban road network expansion and its driving variables: A case study of nanjing city. Int J Env Res Pub He 16 : 2318.

Shiferaw, H., Bewket, W., Alamirew, T., Zeleke, G., Teketay, D., Bekele, K., et al. (2019). Implications of land use/land cover dynamics and prosopis invasion on ecosystem service values in afar region, Ethiopia.Sci Total Environ 675 : 354-366. 
Spake, R., Lasseur, R., Crouzat, E., Bullock, J,M., Lavorel, S., Parks, K.E., et al. (2017). Unpacking ecosystem service bundles: Towards predictive mapping of synergies and trade-offs between ecosystem services. Global Environ Chang 47 : 37-50.

Sze, V., Chen, Y.H., Yang, T.J. \& Emer, J.S. (2017). Efficient processing of deep neural networks: A tutorial and survey. P IEEE105 : 2295-2329.

Tamayo, N.C.A., Anticamara, J.A. \& Acosta-Michlik, L. (2018). National estimates of values of Philippine reefs' ecosystem services. Ecol Econ 146 : 633-644.

Wei, F., Costanza, R., Dai, Q., Stoeckl, N., Gu, X.D., Farber, S, et al. (2018). The value of ecosystem services from giant panda reserves. Curr Biol 28 : 2174-2180. e7.

Wu, K.Y., Ye, X.Y., Qi, Z.F. \& Zhang, H. (2013). Impacts of land use/land cover change and socioeconomic development on regional ecosystem services: The case of fast-growing Hangzhou metropolitan area, china Cities 31 : 276-284.

Yang, Y.Y., Zheng, H., Kong, L.Q., Huang, B.B., Xu, W.H. \& Ouyang, Z.Y. (2019). Mapping ecosystem services bundles to detect high-and low-value ecosystem services areas for land use management. $J$ Clean Prod225 : 11-17.

Yu, D. \& Seltzer, M.L. (2011). Improved bottleneck features using pretrained deep neural networks. Proceedings of the 12th annual conference of the international speech communication association; 27-31 Aug 2011; Florence.

Yuan, Y.J., Wu, S.H., Yu, Y.N., Tong, G.J., Mo, L.J., Yan, D.H., et al. (2018). Spatiotemporal interaction between ecosystem services and urbanization: Case study of nanjing city, china. Ecol Indic95 : 917-929.

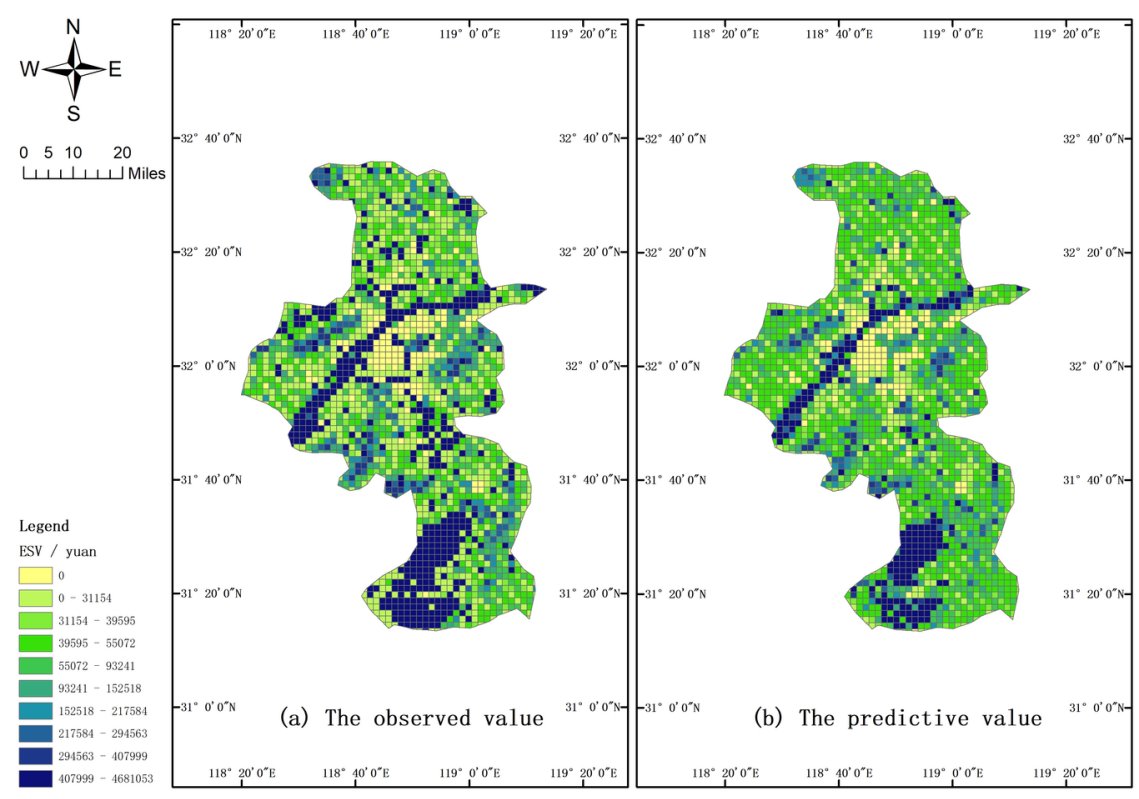




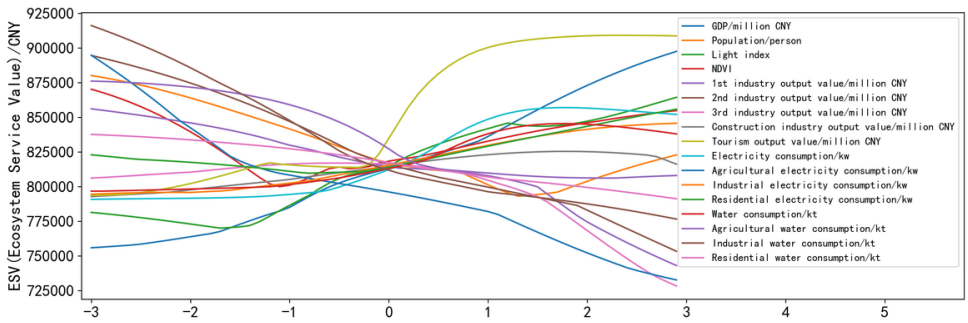

(a)

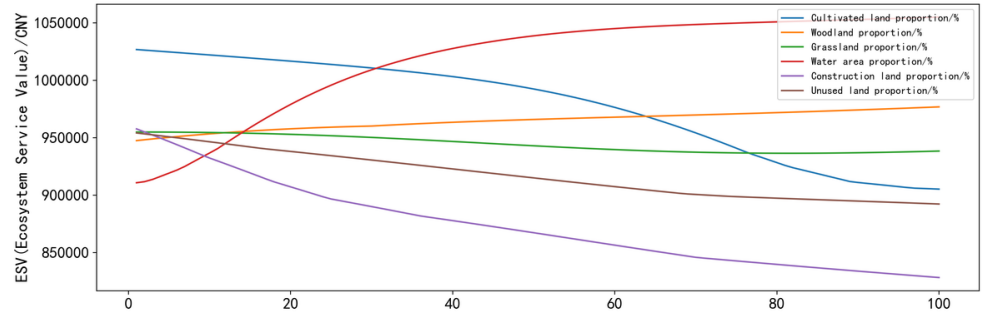

(b)
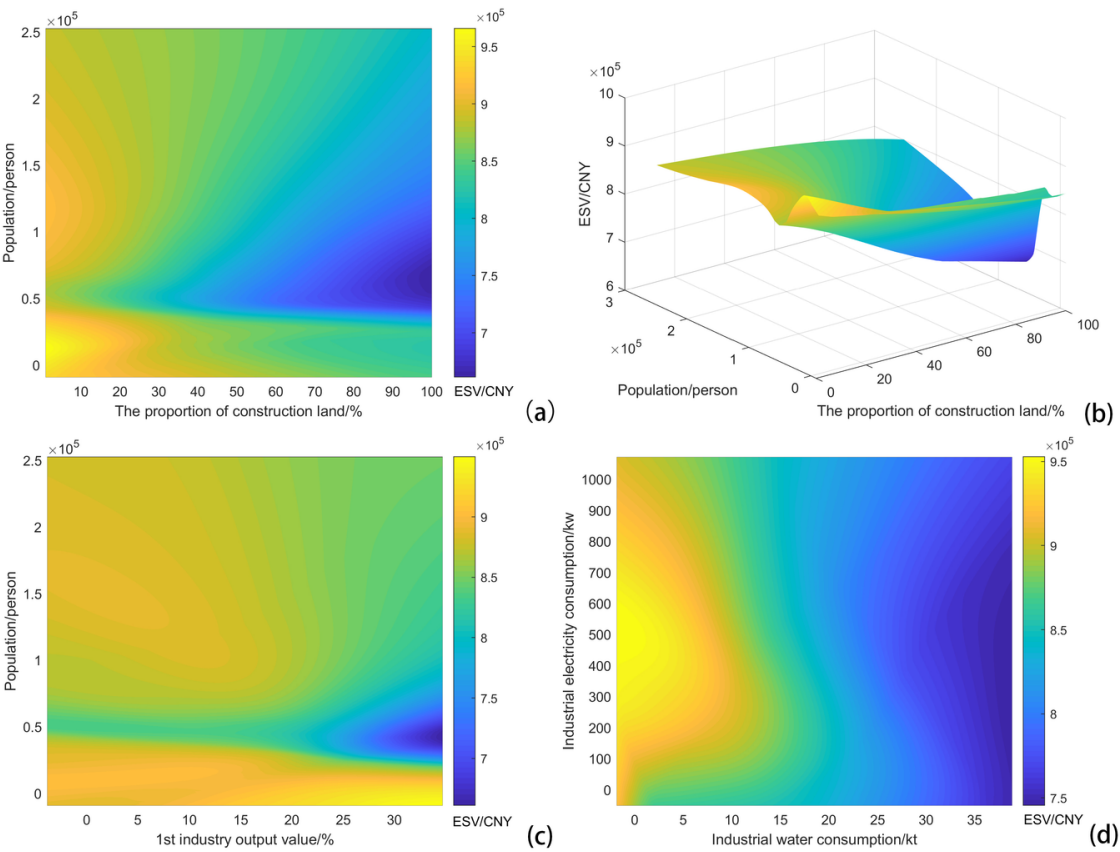